\title{
Patho-morphological and Genotoxic Changes in Induced Aflatoxicosis in White Pekin Ducks (Anas platyrhynchos domesticus)
}

\author{
Imran Ali, S.K. Panda*, S. Pati, A.P. Acharya, S.K. Mishra' ${ }^{1}$, G.R. Jena ${ }^{2}$, \\ G.P. Mohanty ${ }^{3}$, L. Mohanty, S. Das and D. Kumar ${ }^{1}$ \\ ${ }^{1}$ ICAR Regional Centre, Central Avian Research Institute, ${ }^{2}$ Department of Clinical Medicine, \\ ${ }^{3}$ Department of Livestock Production Management, Department of Veterinary Pathology, \\ College of Veterinary Science and Animal Husbandry, Odisha University of Agriculture and \\ Technology, Bhubaneswar, India \\ *Corresponding author
}

\section{Keywords}

Aflatoxin B1, Genotoxic, Gross, microscopic, White Pekin duck

Article Info

Accepted:

12 April 2019

Available Online:

10 May 2019

\section{A B S T R A C T}

The present study attempts to analyze gross and microscopic changes in tissues and genotoxic assessment in bone marrow cells in ducks induced with aflatoxin $\mathrm{B}_{1}$. The study was carried out in 120 nos. of white Pekin ducklings. Ducklings were reared under standard managemental system with ad libitum feed and water etc. for a period of $8^{\text {th }}$ weeks.Aflatoxin $\mathrm{B}_{1}$ added to the feed with different proportion at the dose rate of $6 \mathrm{ppb}$, $12 \mathrm{ppb}, 24 \mathrm{ppb}, \& 48 \mathrm{ppb}$ through premix which were fed to the ducklings of Group 2, 3, 4, 5 respectively, after 3 days with Group 1 as control group. There was a significantly higher chromosomal aberration and micronuclei and lower polychromatic erythrocytes (PCE) in ducks fed with $48 \mathrm{ppb}$. Grossly liver was enlarged, pale, soft and friable with marked congestion in $48 \mathrm{ppbAFB}_{1}$. Marked enlargement with reticulation of kidney was evident in group fed with $48 \mathrm{ppb}$. Bursa was edematous and bursal folds were mildly congested where asthymus was enlarged and pale with petechial. Intestinal wall was slightly thickened with catarrhal exudates and some cases reddish tinged catarrhal exudates in the lumen. Microscopically, at $48 \mathrm{ppb}$, liver revealed vacuolar degeneration of hepatocytes and mild sinusoidal congestion and focal necrotic area. There was tubular degeneration along with interstitial congestion and desquamated tubular lining epithelial cells in kidney. Lymphoid depletion was evident in bursa of Fabricius and thymus. Toxicopathological effect was pronounced at $48 \mathrm{ppb}$ of aflatoxin $\mathrm{B}_{1}$.

\section{Introduction}

Avian species especially ducks, turkeys and chickens are most susceptible to aflatoxin $B_{1}$ (AFB1) toxicity. Aflatoxicosis in poultry is characterized by listlessness, anorexia with lower growth rate; poor feed utilization, decreased body weight, decreased egg production and increased susceptibility to environmental stress and increased mortality. Aflatoxin $\mathrm{B}_{1}$ is a carcinogenic toxin and the main target organ is the liver (hepato-toxic). 
Grossly there is mostly enlarged, pale, friable, and congested liver in broiler chicks fed 100, 200 and $300 \mathrm{ppb}$ aflatoxin up to six weeks of age (Gopinath et al.,2001).Microscopically there is cloudy swelling, hydropic degeneration, fatty changes, congestion, mild bile duct hyperplasia, focal necrosis regenerative changes, heterophilic and lymphocytic infiltrations with hepatic cells forming ductular pattern surrounded by thin layer of fibrous tissue in the liver of broiler chickens fed $1 \mathrm{ppm}$ of aflatoxinB $\mathrm{B}_{1}$ for 28 days (Balachandran and Ramakrishnan, 1987). Kidneys reveal interstitial edema, capillary congestion and tubular epithelial cell degeneration, when chicks were fed with 1 ppm aflatoxin (Gupta et al., 1985). As such ducks are most susceptible to aflatoxin amongst all domesticated poultry (200 fold more than chicken) worldwide were ducks start manifesting morbidities beyond the threshold of 3-4ppb aflatoxin in compounded feed. Further amongst the duck breeds white pekin popular sturdy dual purpose breed, happens to be the most susceptible to toxin. There is morbidity and mortality in ducks due to aflatoxicosis even at lower dose, more than $4 \mathrm{ppb}$ has been published to be affecting ducks productivity adversely. Therefore trial will validate the veracity of these reports and independently contribute to newer findings if any on tolerance of aflatoxin level and toxicopathological changes. The present study attempts to analyze gross and microscopic changes in tissues in ducks induced with aflatoxicosis as well as genotoxic assessment like chromosomal aberration of bone marrow $\&$ Micronucleus assay in different treatment groups.

\section{Materials and Methods}

\section{Experiment}

The study was carried out in 120 nos. of white Pekin ducklings which were procured from Central Poultry Development Organization and Training Institute (CPDOTI), Bangalore. Ducklings were acclimatized for 2 days at Instructional Livestock farm Complex, Odisha University of Agriculture and Technology, Bhubaneswar and were randomly divided into 5 groups with four treatment groups and one control group comprising twenty four birds in each group with 3 replicates. Ducklings were reared under standard managemental system with ad libitumfeed and water etc for a period of 8 weeks.Standard duck feed was procured from commercial manufacturer by replacing maize with wheat to make the feed free from aflatoxin. Feed was tested negative for any aflatoxin before feeding to the experimental ducks. Purified Aflatoxin $\mathrm{B}_{1}$ toxin was procured from commercial sources (Himedia) and these toxins added to the feed with different proportion at the dose rate of $6 \mathrm{ppb}$, $12 \mathrm{ppb}, 24 \mathrm{ppb}$, and $48 \mathrm{ppb}$ through premix which were fed to the ducklings of Group 2, 3, 4, 5 respectively, after 3 days. Group 1 was control group fed with normal feed.

\section{Gross pathology}

At the end of the $8^{\text {th }}$ weeks, 6 birds from each group were sacrificed by dislocation of the head. A detailed necropsy was conducted in each bird to observe the gross lesions.

\section{Histopathology}

Representative portion of the appropriate tissues such as liver, lungs spleen, kidney, heart, bursa of Fabricius, thymus and intestine were collected in $10 \%$ neutral buffered formalin solution. After fixation, tissue sample were washed overnight in running tap water and then dehydrated by ascending grades of ethyl alcohol, cleared in xylene and embedded in paraffin wax for blocking. Paraffin embedded tissue were sanctioned at 5 $\mu \mathrm{m}$ thickness and stained by Haematoxylin and Eosin for histopathological examination. 


\section{Assessment of genotoxic effects}

For assessment of genotoxic effect of Aflatoxin $\mathrm{B}_{1}$ two experiments were performed i.e. (a) Chromosomal aberration test and (b) micro nucleus test as per experimental design (TableNo.1). The positive control group was injected with cyclophosphamide which is known genotoxic compound at the dose rate of $20 \mathrm{mg} / \mathrm{kg}$ body weight intraperitoneally 24 hrs before sacrifice. The cyclophosphamide injected ducks were observed for clinical signs, behavioral changes and mortality. Samples were collected at the end of treatment and then sacrifice.

\section{a) Chromosomal aberration test}

Chromosomal aberration assay was carried out in bone marrow cells as per the methods suggested by Malhi and Grover (1987) and Chauhan et al.,(2000).

\section{b) Bone marrow micronucleus test}

Micronuclei assay was carried out in bone marrow cells by the method suggested by Hayashi et al., (1983) and Chauhan et al., (2000).

\section{Results and Discussion}

\section{Genotoxicity assessment}

\section{Chromosomal aberration assay}

The structural chromosomal aberrations like gaps, breaks, fragments, ring and pulverization (Fig. 1) of chromosomes were observed in bone marrow cells of different treatment groups. No chromosomal aberration was found in negative control group. The mean structural chromosomal aberrations in groups 1, 2, 3, 4 and 5 are shown in TableNo.2. There was a significantly highest chromosomal aberration value in Gr-5 (48ppb) compared to all other groups including control.

\section{Micronucleus assay}

The mean number of micronuclei/2000 polychromatic erythrocytes (PCE) in bone marrow, in groups $1,2,3,4$ and 5 (positive control) is shown in (Table No.3). No micronucleus was found in negative control group. The average number of micronuclei (MN) per 2000 PCE in Gr-5(48ppb) was significantly highest as compared to other groups. The micronuclei (Fig. 2) observed in Gr-3, Gr-4 was significantly higher than Gr-2, (6ppb) Gr-1 (healthy control) and Gr-4, Gr-3, Gr-2 was significantly higher than that of Gr1. The mean number of polychromatic erythrocytes (PCE) /200 total erythrocytes (TE) in bone marrow, in groups 1,2,3,4 and 5 (positive control) is shown in Table No.4.The mean number of PCE/200 Total Erythrocytes (TE) in bone marrow cells of animals in $\mathrm{Gr}-2$ did not differ significantly from Gr-1. Similarly, Gr-3 did not differ significantly from Gr-4 but they were significantly decreased from Gr-1 and Gr-2. Gr-5 (48ppb) decreased significantly compared to all the groups. The importance of chromosomal aberration as a proximate cause of bone marrow toxicity was discussed by Heddle et al., (1981). As per findings by Jhonson et al., (1998) there are three major types of genotoxic effects gene mutation, chromosomal aberrations and DNA effects, because no single in vitro assay is capable of detecting all three types, a battery of test is recommended.

\section{Gross pathology}

There were mild changes of enlarged and pale liver in group fed with $24 \mathrm{ppb} \mathrm{AFB}_{1}$. In group of $48 \mathrm{ppb}$ there was enlarged, pale, soft and friable liver. Liver also revealed marked congestion with adjacent pale patches and enlargement of liver (Fig. 3). There was slight enlargement of kidney with paleness in group fed with 24ppb $\mathrm{AFB}_{1}$. Marked enlargement with reticulation of kidney was evident in 
group fed with $48 \mathrm{ppb} \mathrm{AFB}_{1}$ (Fig. 4). In heart there was cardiac dilatation and ventricles were empty in 24 ppb group. In 48 ppb group there was petechiae on the epicardial surface in some cases along with cardiac dilatation in majority of the cases. Lungs in few cases of $48 \mathrm{ppb}$ revealed mild congestion and edema. Spleen was also slightly congested in $48 \mathrm{ppb}$. Bursa was edematous and bursal folds were mildly congested. Thymus was slightly enlarged and pale in group fed with $24 \mathrm{ppb}$ $\mathrm{AFB}_{1}$ where as in $48 \mathrm{ppb}$ there was enlarged and pale thymus with petechial hemorrhages throughout (Fig. 5). Intestinal wall was slightly thickened with catarrhal exudates and mucus in the lumen at $24 \mathrm{ppb}$ level of $\mathrm{AFB}_{1}$ At $48 \mathrm{ppb}$ there was thickening of intestinal wall with reddish tinged catarrhal exudates in the lumen (Fig. 6). There are various reports of similar gross lesions in liver, kidney and other tissues of broiler chicken, quails and other avian species by Sawhney et al., (1973), Chang and Hamilton (1982), Balachandran and Ramakrishnan (1987b), Panda et al., (1987), Johri et al., (1989), Rao et al., (1990), Sadana et al., (1992), Kumar et al., (1993), Kumar and Balachandran (1998), Gopinath et al., (2001), Mundas and Rao (2001), Madheswaran et al., (2005) and Gounalan (2005).

\section{Histopathology}

In liver there was no significant histopathological finding in treatment groups of $6 \mathrm{ppb}$ to $24 \mathrm{ppb}$. However, there were some alterations in group of $48 \mathrm{ppb}$ of $\mathrm{AFB}_{1}$. Liver revealed vacuolar degeneration of hepatocytes and mild sinusoidal congestion (Fig. 7). Focal necrotic area, focal necrosis of hepatocytes with mild sinusoidal congestion (Fig. 8) and focal necrotic area with fibrosis was evident at places. Some cases revealed bile duct hyperplasia with fibrotic proliferation, infiltration of mononuclear cells around the bile duct and perivascular infiltration with inflammatory cells. Reports of histological alterations in liver by Balachandran and Ramakrishnan (1987a), Giambrone et al., (1985b), Rao et al., (1990) Miazzo et al., (2000) (Gupta et al., 2002) and Madheswaran et al., (2005b) in different avian species are in agreement with current findings. Kidney also revealed some changes in group of 48 $\mathrm{ppbAFB}_{1}$. Interstitial congestion along with edema and haemorrhages, homogenous \& proteinaceous material in the tubular lumen, and swelling of the tubular epithelium occluding the lumen of the tubules were evident. There was focal infiltration of inflammatory cells in few cases. Tubular degeneration along with interstitial congestion and desquamated tubular lining epithelial cells (Fig. 9) also noticed. Increased bowman's space of glomeruli and cellular swelling of tubular epithelium was a feature in few cases. Balachandran and Ramakrishnan (1987b), Fernandez et al., (1994), Kumar and Balachandran (1998) and Madheswara et al., (2005b) reported similar changes in kidney in various poultry species. In heart there was myocardial congestion and intermycial edema (Fig. 10), and disruption of muscle fibre was commonly evident in case of $48 \mathrm{ppb}$ group. In lungs, focal infiltration of inflammatory cells of the para bronchi (Fig. 11), Perivascular edema and infiltration of inflammatory cells and fibroblast were some of the findings in $48 \mathrm{ppb}$ group. Splenic congestion along with depletion of red pulp was evident in few cases of group fed with 48 $\mathrm{ppb}$ of $\mathrm{AFB}_{1}$.Interfolicular edema and depletion of lymphocytes in the bursal follicles (Fig. 12) were evident in group fed with $48 \mathrm{ppb}$ of $\mathrm{AFB}_{1}$. Lymphoid depletion also reported by Kumar et al., (1993), Bakshi et al., (1995), Singh and Gill (1996), Kumar and Balachandran (1998) and Perozo and Rivera (2003). Depletion of thymic cells along with edema, hemorrhage and infiltration of mononuclear cells (Fig.13) were found in few cases of group fed with 48 ppb of $\mathrm{AFB}_{1}$. 
Table.1 Experimental protocol of genotoxic study

\begin{tabular}{|l|c|c|c|c|c|c|}
\hline \multicolumn{1}{|c|}{ GROUP } & G-1 & G-2 & G-3 & G-4 & G-5(positive control) & $\begin{array}{c}\text { G6(negative } \\
\text { control) }\end{array}$ \\
\hline DOSE & Aflatoxin & $\begin{array}{c}\text { Aflatoxin } \\
\mathrm{B}_{1} @ 6 \mathrm{ppb}\end{array}$ & $\begin{array}{c}\text { Aflatoxin } \\
\text { B } 12 \mathrm{ppb}\end{array}$ & $\begin{array}{c}\text { Aflatoxin } \\
\mathrm{B}_{1} @ 24 \mathrm{ppb}\end{array}$ & $\begin{array}{c}\text { B } @ 48 \mathrm{ppb} \\
\text { Cyclophosphamide@ 20mg/k }\end{array}$ & $\begin{array}{c}\text { g body wt } \\
---\end{array}$ \\
\hline ROUTE & orally & orally & orally & orally & Intra peritoneally & --- \\
\hline NO.OF DUCKS & 6 & 6 & 6 & 6 & 6 & 6 \\
\hline
\end{tabular}

Table.2 Mean structural chromosomal aberrations in groups

\begin{tabular}{|c|c|c|c|c|}
\hline $\begin{array}{c}\text { Group-1 } \\
\text { (healthy control) }\end{array}$ & $\begin{array}{c}\text { Group-II } \\
(6 \mathrm{ppb})\end{array}$ & $\begin{array}{c}\text { Group-III } \\
(12 \mathrm{ppb})\end{array}$ & $\begin{array}{c}\text { Group-IV } \\
(24 \mathrm{ppb})\end{array}$ & $\begin{array}{c}\text { Group-V } \\
(48 \mathrm{ppb})\end{array}$ \\
\hline $1.162^{\mathrm{a}} \pm 0.012$ & $1.727^{\mathrm{a}} \pm 0.025$ & $3.255^{\mathrm{b}} \pm 0.025$ & $4.072^{\mathrm{c}} \pm 0.017$ & $10.430^{\mathrm{d}} \pm 0.021$ \\
\hline
\end{tabular}

Table.3 Mean micronuclei/2000 polychromatic erythrocytes (PCE)

\begin{tabular}{|c|c|c|c|c|}
\hline $\begin{array}{c}\text { Group-1 } \\
\text { (healthy control) }\end{array}$ & Group-II (6ppb) & $\begin{array}{c}\text { Group-III } \\
(12 \mathrm{ppb})\end{array}$ & $\begin{array}{c}\text { Group- } \\
\text { IV(24ppb) }\end{array}$ & Group-V (48ppb) \\
\hline $8.040^{\mathrm{a}} \pm 0.018$ & $13.83^{\mathrm{b}} \pm 0.024$ & $21.08^{\mathrm{c}} \pm 0.018$ & $24.720^{\mathrm{c}} \pm 0.014$ & $61.920^{\mathrm{d}} \pm 0.022$ \\
\hline
\end{tabular}

Table.4 Mean polychromatic erythrocytes (PCE) /200 total erythrocytes (TE)

\begin{tabular}{|c|c|c|c|c|}
\hline $\begin{array}{c}\text { Group-1 } \\
\text { (healthy control) }\end{array}$ & Group-II(6ppb) & Group-III(12ppb) & $\begin{array}{c}\text { Group- } \\
\text { IV(24ppb) }\end{array}$ & Group-V (48ppb) \\
\hline $107.566^{\mathrm{c}} \pm 0.322$ & $104.233^{\mathrm{c}} \pm 0.233$ & $90.300^{\mathrm{b}} \pm 0.191$ & $89.133^{\mathrm{b}} \pm 0.169$ & $61.083^{\mathrm{a}} \pm 0.256$ \\
\hline
\end{tabular}

Fig.1\&2 Photograph showing structural chromosomal aberrations like pulverization \& Photograph showing Micronucleus in RBC stained with May Grunewald stain
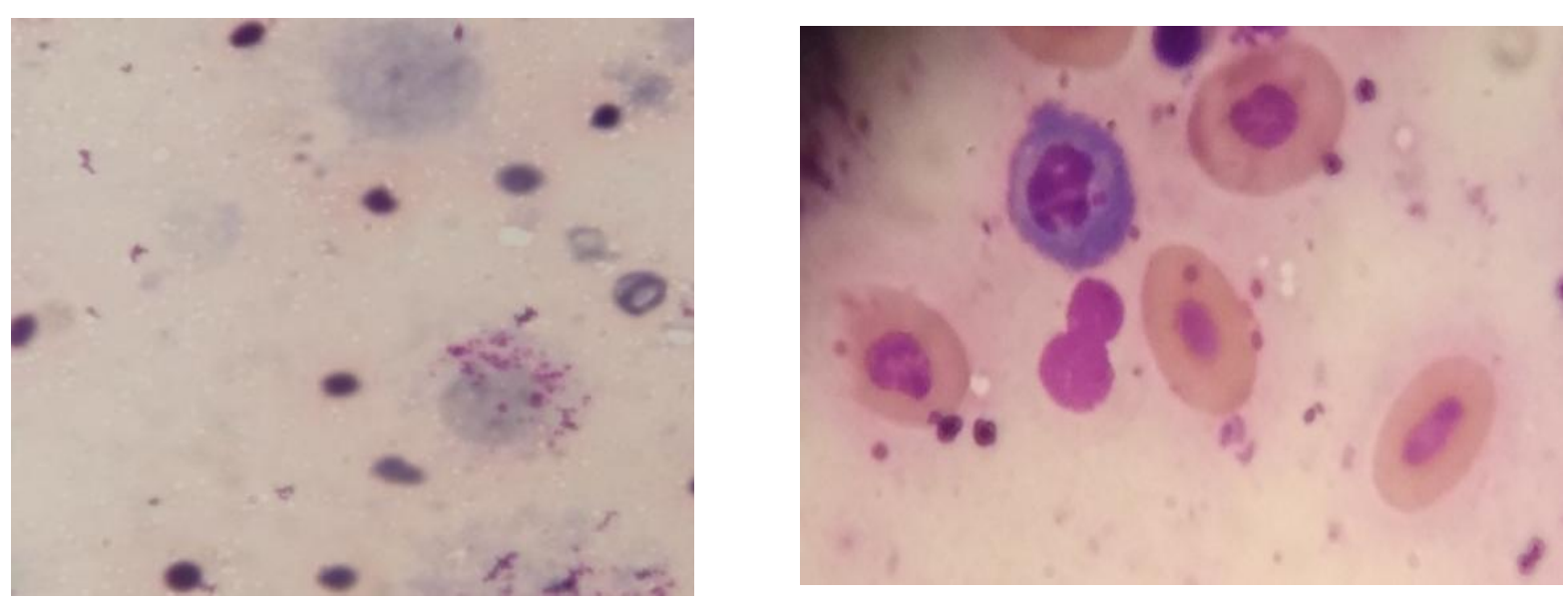
Fig.3\&4 Gross photograph showing marked congestion with adjacent pale patches with enlargement of liver \& Gross photograph showing marked enlargement with reticulation of kidney
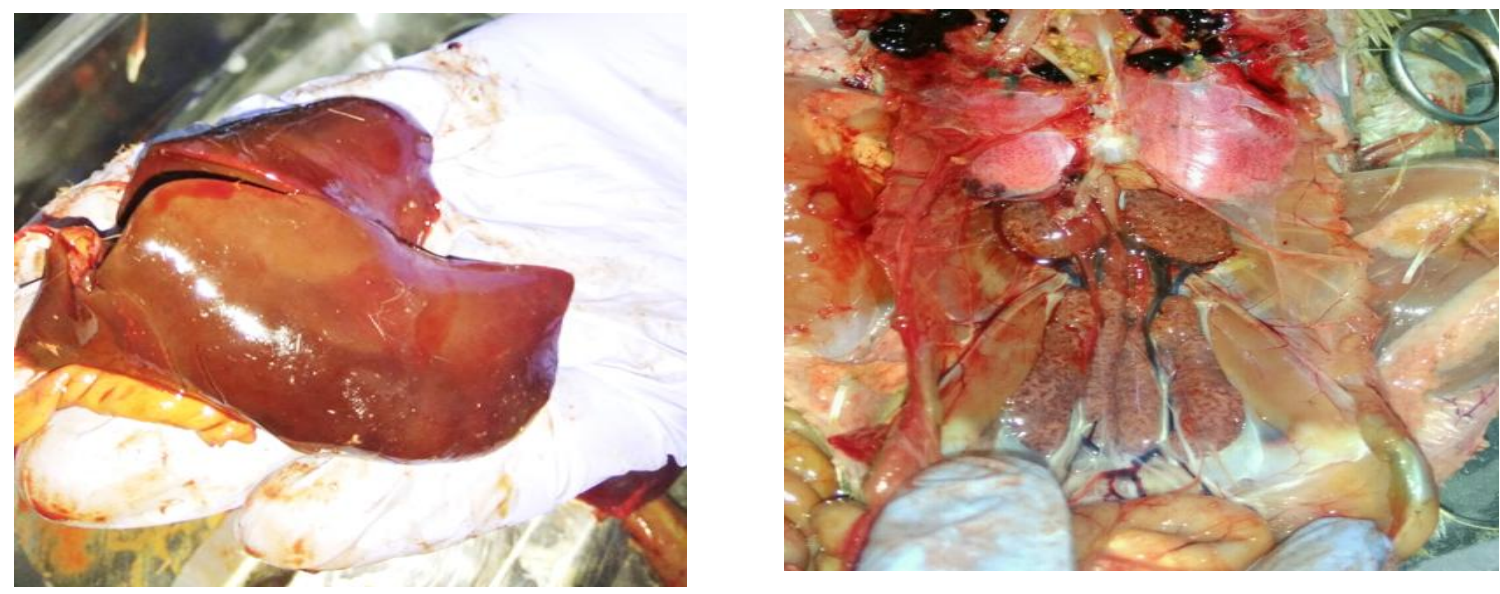

Fig.5\&6 Gross photograph showing enlarged and pale thymus with petechial hemorrhages \& Gross photograph showing thickening of intestinal wall with reddish tinged catarrhal exudates in the lumen
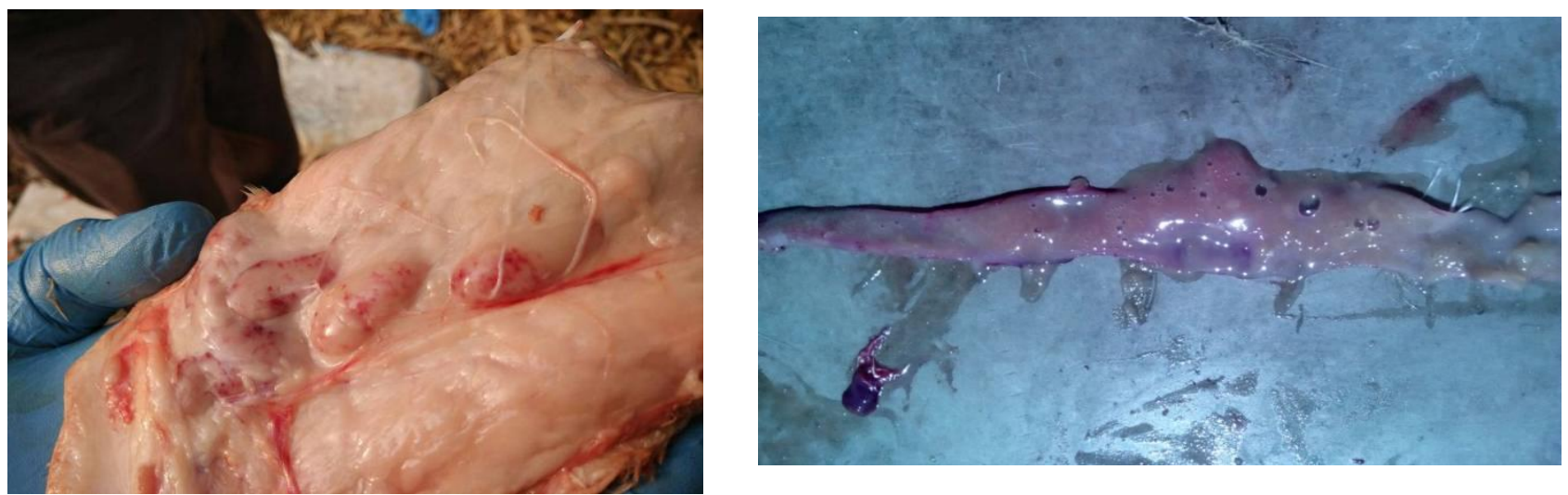

Fig.7\&8 Photomicrograph of Liver showing vacular degeneration of hepatocytes and mild sinusoidal congestion (H\&E X 400) \& Photomicrograph of Liver showing Focal necrosis of hepatocytes and congestion (H\&E X 400)
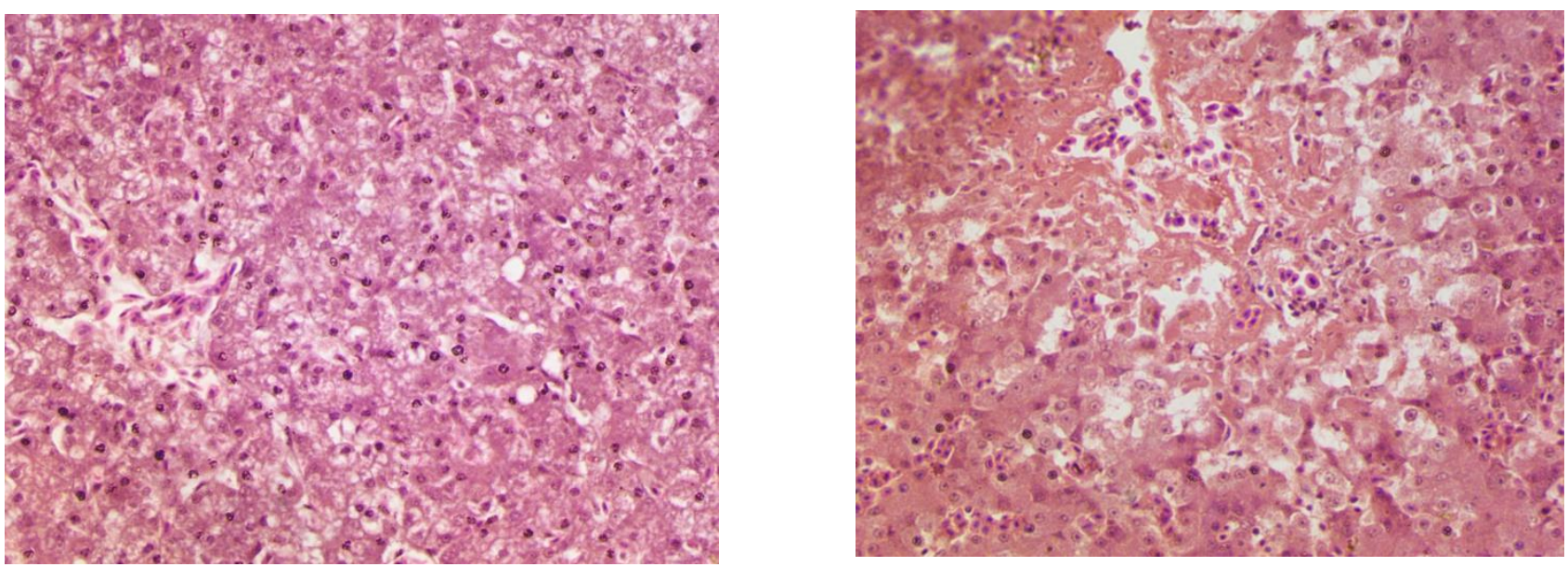
Fig.9\&10 Photomicrograph of Kidney showing Tubular degeneration and desquamated tubular lining with inter tubular congestion (H\&E x 400) \& Photomicrograph of Heart showing Myocardial congestion and Oedema (H\&E x 100)
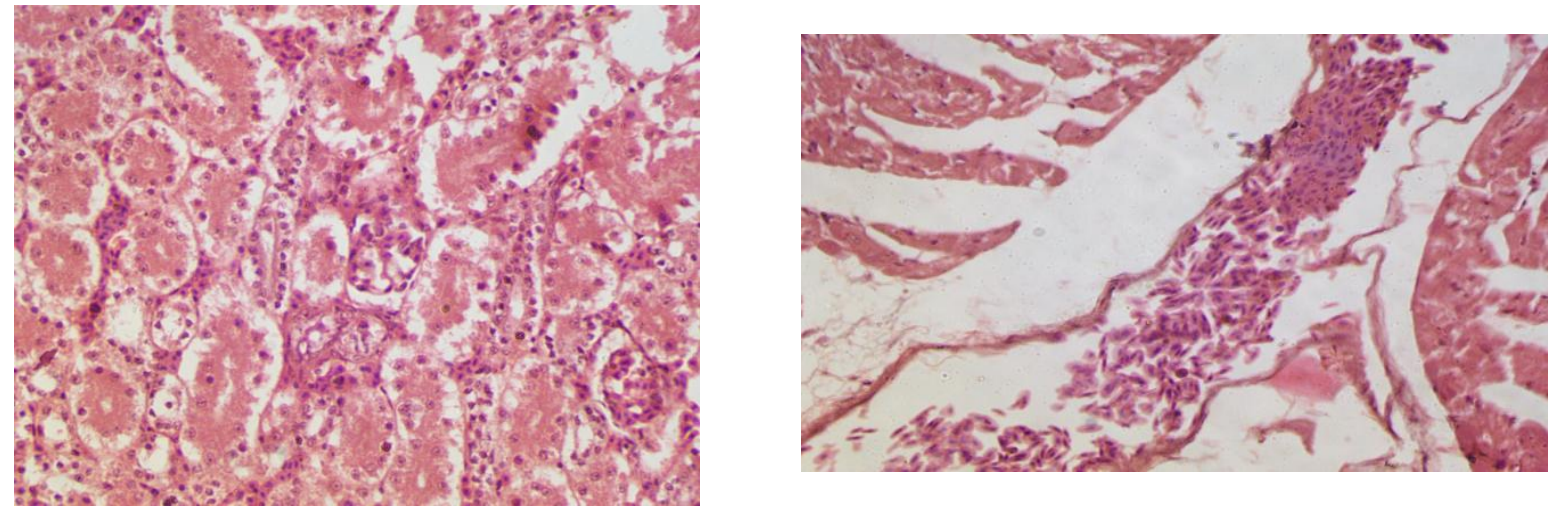

Fig.11\&12 Photomicrograph of lungs showing Focal infiltration of inflammatory cells of the para bronchi (H\&E x 400) \& Photomicrograph of Bursa of fabricious showing depletion of lymphocyte in the bursal follicle (H\&E x 400)
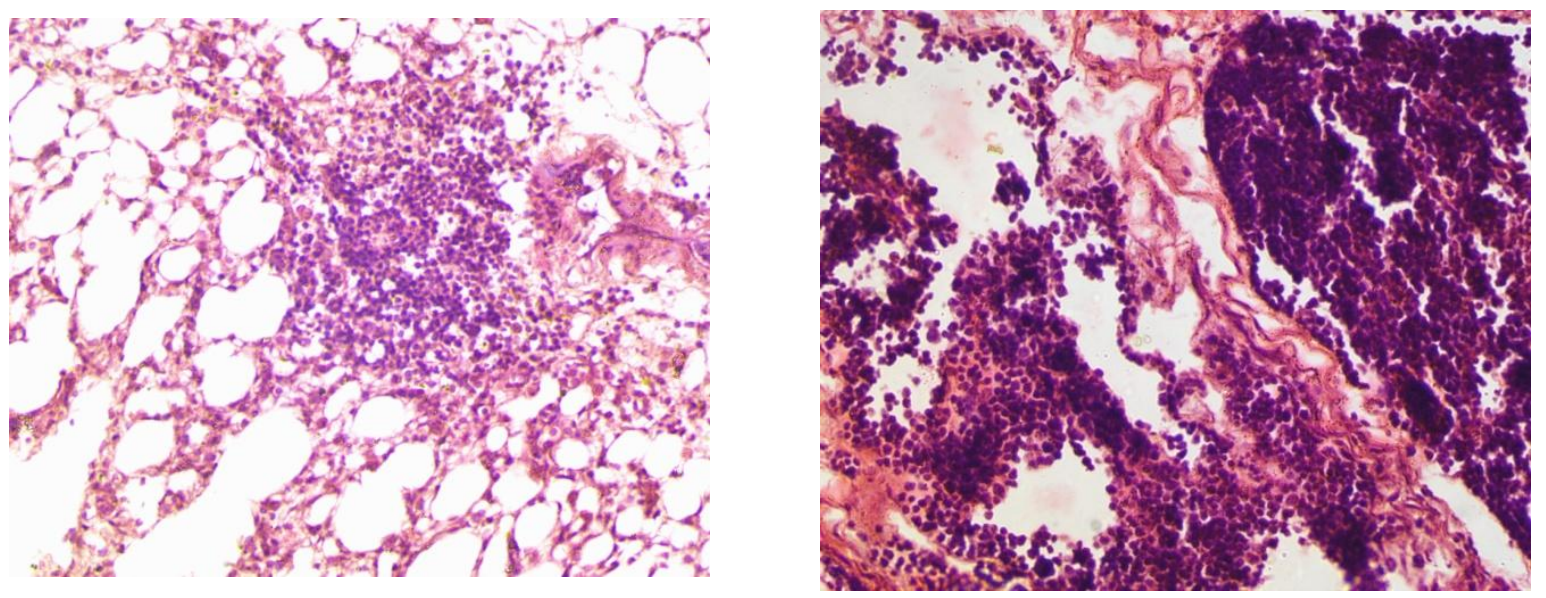

Fig.13\&14 Photomicrograph of thymus showing depletion of thymic cell oedema, hemorrhage and infiltration of mononuclear cells (H\&E x 400) \& Photomicrograph of intestine showing Desquamation of mucosal villi and presence of desquamated cellular debris (H\&E x 400)
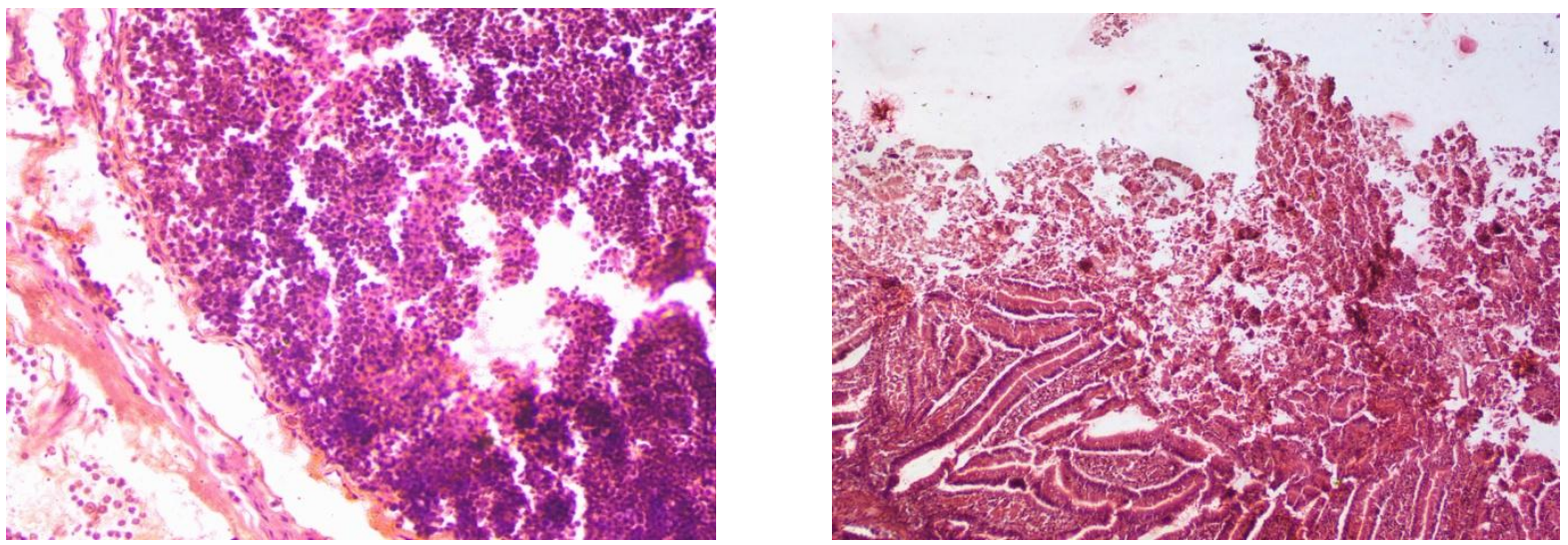
Desquamation of intestinal lining epithelial cells, increased goblet cell activity in the mucosal villi and presence of mucous on the surface and presence of desquamated cellular debris (Fig. 14) were the distinct pathological features in group fed with $48 \mathrm{ppb}$ of $\mathrm{AFB}_{1}$. Balachandran and Ramakrishnan (1987b) observed moderate cartarrhal enteritis in broiler chicken fed 1 ppm AF for 28 days.

Sadana et al., (1992) reported that feeding 0.5 ppm AFB1 to young Japanese quail from 0-6 weeks resulted in enteritis characterized by mononuclear cell infiltration and necrosis of superficial epithelium. Kumar and Balachandran (1998) observed catarrhal changes, necrosis, desquamation and lymphocytic or mononuclear cell infiltration of intestinal mucosa in the broilers fed $1 \mathrm{ppm}$ AF for 28 days. In broiler chicks fed $0.5 \mathrm{ppm}$ AFB1 from 3 to 30 days of age, there were mild multifocal haemorrhages in the mucosa, moderate goblet cell hyperactivity and denudation of intestinal mucosa (Ahamad and Vairamuthu, 2001). Srivani et al., (2003) reported that in broiler chicks fed $1 \mathrm{ppm}$ AFB1 for up to 42 days of age submucosal haemorrhages and disrupted epithelial villi were observed. Madheswaran et al., (2005b) reported that feeding AF (3 ppm) revealed increased goblet cell activity, vacuolar degeneration and necrosis of villi epithelium and fibrosis of lamina propria in the intestine of all toxins fed quails. It is concluded from the study that there was toxicopathological effect at $48 \mathrm{ppb}$ of aflatoxin $\mathrm{B}_{1}$ in white pekin duck.

\section{Acknowledgement}

The authors are thankful to the Dean, College of Vety. Sci \& AH, OUAT, Bhubaneswar and Director ICAR- NASF for providing necessary facilities for smooth conduction and completion of the research work.

\section{References}

Ahamad, D.B. and S. Vairamuthu. 2001. Individual and combined effects of citrinin and aflatoxin B1 in broiler chicks: A pathomorphological study. Indian J. Vet. Pathol., 25: 32-34.

Bakshi, C.S., A. Sikadar and S.K. Chattopadhyay. 1995. Experimental aflatoxicosis in commercial broilers: Pathomorphological studies. Indian J. Vet. Pathol., 19: 112-115.

Balachandran, C. and R. Ramakrishnan. 1987. Influence of dietary aflatoxin on growth rate and haematology in broiler chicken. Indian J. Poult. Sci., 22: 105-108.

Chang, C.F. and P.B. Hamilton. 1982. Experimental aflatoxicosis in young Japanese quail. Poult. Sci., 61: 869-874

Chauhan, L.K.S., Pant, N., Gupta, S.K., and Srivastava, S.P. (2000). Induction of chromosome aberrations, micronucleus formation and sperm abnormalities in mouse following carboturan exposure. Mutat Res., 465: 123-129

Fernandez, A., M.T. Verde, M. Gascon, J. Ramos, G. Gomez, D.F. Luco and G. Chavez. 1994. Variations of clinical and biochemical parameters of laying hens and broiler chicken fed aflatoxin containing feed. Avian Pathol., 23: 37- 47.

Giambrone, J.J., U.L. Diener, N.D. Davis, V.S. Panangala and F.J. Hoerr. 1985b. Effects of aflatoxin on young turkeys and broiler chickens. Poult. Sci., 64:1678-1684.

Gopinath, C.R., C.V. Gowdh, G. Devegowda and B. Umakantha. 2001. Studies on supplementation of Livfit Vet to alleviate the effect of aflatoxin in broilers diet. Indian J. Poult. Sci., 36: 50-53.

Gounalan, S. 2005. Pathology of Newcastle disease virus and its interaction with mycotoxins in layer-type chicken. Ph.D., thesis approved by Tamil Nadu Veterinary and Animal Sciences University, Chennai

Gupta, K.A., K. Mohammad, K.A. Naveen, 
Ajay Varma, P. Balakrishnan and P.B. Rai. 2002. Pathomorphological studies on naturally occurring mycotoxicoses induced visceral gout in chicken. Indian Vet. J., 79: 443-445.

Hayashi M., T. Sofuni and M. Ishidate (1983) An application of acridine orange fluorescent staining to the micronucleus test. Mutat Res., 120: 241-247

Heddle, J. A and Salamone, M.F.(1981) Chromosomal aberration and bone marrow toxicity. Environ Health Perspect. 39: 23-27

Jhonson, G.M., Upman, P.J and Wallin R.F. (1998). A practical guide to ISO 10993-3: Genotoxicity Medical Device \& Diagnosis Industry Magazine. ISO 10993.

Johri, T.S., R. Agarwal and V.R. Sadagopan. 1989. Effect of commonly occurring levels of dietary aflatoxin on the performance of Rhode Island Red x White Leghorn cross, White Leghorn and quail starter chicks. Indian J. Anim. Sci., 59: 378-384

Kumar, A.A., S.K. Chanda, A.T. Rao, P.C. Bisoi and P.K. Mishra. 1993. Clinicopathological changes in experimental aflatoxicosis in quail. Indian J. Poult. Sci., 28: 150-153.

Kumar, R. and C. Balachandran. 1998. Pathological changes in broiler chicken fed aflatoxin and cyclopiazonic acid. XV Annual Conference of Indian Association of Veterinary Pathologists, November 9-11, Mannuthy, Kerala

Madheswaran, R., C. Balachandran and B. Murali Manohar. 2005b. Pathological effects of feeding aflatoxin and T-2 toxin in Japanese quail. Indian J. Vet. Pathol., 29: 23-26

Malhi, P.K and Grover, I.S (1987). Genotoxic effects of some organophophorus pesticides II in vivo chromosomal aberration bioassay in bone marrow cell in rat. Mutat Res.,
188:45-51

Miazzo, R., C.A. Rosa, E.C. Carvalho, C. Magnoli, S.M. Chiacchiera, G. Palacio, M.Saenz, A. Kikot, E. Basaldella and A. Dalcero. 2000. Efficacy of synthetic zeolite to reduce the toxicity of aflatoxin in broiler chicks. Poult. Sci., 79: 1-6.

Mundas, S. and D.G.K. Rao. 2001. Histological changes in liver by aflatoxin and fenvalerate treated broiler birds. Indian Vet. J., 78: 1152-1153

Panda, B.K., N.K. Praharaj, T.S. Johri and R.L. Sah. 1987. Experimental aflatoxicosis in Japanese quails: Evidence of some biochemical changes. Indian J. Poult. Sci., 22: 359-362.

Perozo, F and S. Rivera. 2003. Effect of aflatoxin B1 exposure and selenium supplementation on immune response in broilers. Indian Vet. J., 80: 1218-1221.

Rao, J.R., N.N. Sharma, P.K.R. Iyer and A.K. Sharma. 1990. Interaction between Eimeria uzurainfection and aflatoxicosis in Japanese quail (Coturnix coturnix japonica). Vet. Parasitol., 35: 259-267

Sadana, J.R., R.K. Asrani and R.K.P. Gupta. 1992. Pathology of experimental aflatoxicosis in young Japanese quail. Indian J. Vet. Pathol., 27: 198-202

Sawhney, D.S., D.V. Vadehra and R.C. Baker. 1973. Aflatoxicosis in laying Japanese quail. Poult. Sci., 52: 465-473.

Singh, C. and B.S. Gill. 1996. Studies on aflatoxicosis in relation to coccidiosis in poultry. Indian J. Vet. Pathol., 20: 65-66.

Srivani, M., Y. Anjaneyulu, A. Seshagiri Rao, B.J.R. Sarma and M.V.L.N. Raju. 2003. Efficacy of immunomodulators on induced aflatoxicosis in broiler chicks-A pathological study. Indian J. Vet. Pathol., 27: 27-29.

\section{How to cite this article:}

Imran Ali, S.K. Panda, S. Pati, A.P. Acharya, S.K. Mishra, G.R. Jena, G.P. Mohanty, L. Mohanty, S. Das and Kumar, D. 2019. Patho-morphological and Genotoxic Changes in Induced Aflatoxicosis in White Pekin Ducks (Anas platyrhynchos domesticus). Int.J.Curr.Microbiol.App.Sci. 8(05): 1225-1233. doi: https://doi.org/10.20546/ijcmas.2019.805.139 